Rose, C. F., Verkhratsky, A., \& Parpura, V. (2013). Astrocyte glutamine synthetase: Pivotal in health and disease. Biochemical Society Transactions, 41(6), 1518-1524.

Final publication available at : https://doi.org/10.1042/BST20130237

\title{
Astrocyte glutamine synthetase: pivotal in health and disease
}

Christopher F. Rose ${ }^{1}$, Alexei Verkhratsky ${ }^{2}$ and Vladimir Parpura ${ }^{3,4}$

${ }^{1}$ Hepato-Neuro Laboratory, Hôpital Saint-Luc (CRCHUM), Université de Montréal, Québec, Canada

${ }^{2}$ Faculty of Life Sciences, University of Manchester, UK

${ }^{3}$ Department of Neurobiology, Center for Glial Biology in Medicine, Civitan International Research Center, Atomic Force Microscopy \& Nanotechnology Laboratories, and Evelyn F. McKnight Brain Institute, University of Alabama, Birmingham, USA; ${ }^{4}$ Department of Biotechnology, University or Rijeka, 51000 Rijeka, Croatia.

\section{Corresponding author:}

Christopher F. Rose Ph.D., Neuroscience Research Unit, Hôpital Saint-Luc (CRCHUM),

Université de Montréal, Québec, Canada. Phone: +1 514890 8000, ext. 35739; email:

christopher.rose@umontreal.ca

\section{List of abbreviations:}

Disclosures: The authors have no conflicts to disclose

Key Words: astrocytes, glutamine synthetase, glutamate, glutamine, GABA, ammonia 


\section{Astrocytes as homeostatic cells in the central nervous system}

Out of four main classes of neuroglial cells of the central nervous system (astroglia, oligodendroglia, NG2 glia and microglia) astrocytes are arguably the most diverse. Indeed, astroglial cells include a huge variety of phenotypes with very different morphology and physiological properties. The largest and most characterised types of astroglia are represented by the protoplasmic astrocytes of the grey matter and fibrous astrocytes of the white matter. Morphological appearance of these cells as well as their physiology differ substantially between various brain regions. Another main group of astroglial cells covers the radial glia, which are bipolar cells with a small cell body and main processes, one of which forms endfeet on the ventricular wall and the other at the pial surface. Radial glia are the main glial type of the embryonic brain and generally absent from the mature brain with the exception of the retina (Müller glia) and cerebellum (Bergmann glia). Astrocytes are further classified into the velate astrocytes of the cerebellum, the interlaminar and polarised astrocytes of the primate cortex, tanycytes (found in the periventricular organs, the hypophysis and the raphe part of the spinal cord), pituicytes in the neuro-hypophysis, and perivascular and marginal astrocytes. Astroglia also include several types of cells that line the ventricles or the subretinal space, namely ependymocytes, choroid plexus cells and retinal pigment epithelial cells (see ${ }^{[1,2]}$ for review and references).

All these highly diverse cells are united by their function which lies in maintaining the homeostasis of the nervous system ${ }^{[1]}$. To cater for this, astrocytes perform many different functions, which embrace every known house-keeping and homeostatic task in the CNS (for detailed reviews see ${ }^{[3-12]}$. Astroglial cells are fundamental for brain development being, for example, chief promoters and supporters of synaptogenesis, synaptic maturation and maintenance ${ }^{[13,14]}$. In the adult brain these are astrocytes which act as stem cells in the neurogenic niches ${ }^{[15]}$. Astrocytes define overall brain architecture by forming glial barriers at the pia mater and between the brain parenchyma and vasculature; they divide the grey matter into neuro-vascular units and contribute to regulation of local blood flow; they are primary elements of brain ion homeostasis, they control extracellular $\mathrm{pH}$, they provide neurones with metabolic substrates and release scavengers of reactive oxygen species (for detailed reviews see ${ }^{[3-12]}$ ). Astrocytes are also critical for numerous systemic homeostatic functions such as central chemoception ${ }^{[16-18]}$ and regulation of sleep ${ }^{[19]}$. In the present essay we shall concentrate on a single homeostatic function of astroglia, the function which relates to their ability to maintain turnover of two principal neurotransmitters in the brain, glutamate and GABA, this function being accomplished by glutamate, GABA and glutamine transporters, and by astroglial specific enzyme, the glutamine synthetase (GS).

\section{Astrocytes in glutamatergic neurotransmission: glutamate uptake and release}

Fundamentally astrocytes contribute to the homeostasis and regulation of extracellular level of three key neurotransmitters in the CNS, represented by glutamate, GABA and adenosine ${ }^{[8,20,21]}$. 
Astroglial role is multifaceted; (i) it includes an uptake of these neurotransmitters from the extracellular cleft, which defines the time course of neurotransmission and (at least in case of glutamate) preventing toxicity; (ii) astrocytes are also capable or releasing neurotransmitters through vesicular and non-vesicular pathways and (iii) astrocytes catabolise neurotransmitters into intermediates, which are then sent back to neurones to be transformed into active molecules, thus maintaining synaptic transmission.

\section{Astroglial uptake of glutamate}

Glutamic acid, or glutamate, is an amino acid, which in the CNS, acts as the main excitatory neurotransmitter released from presynaptic terminals through vesicular exocytotic mechanism. To make this mechanism function properly both extra- and intracellular glutamate dynamic should be tightly controlled. Glutamate should be removed from the synaptic cleft and at the same time the synaptic cleft should be guarded from extrasynaptic glutamate or glutamate spillover from neighbouring synapses. Simultaneously the glutamate inside the presynaptic terminal should be rapidly replenished. It is important to note that neurones are incapable of $d e$ novo synthesis of glutamate; the latter is synthesized in astrocytes ${ }^{[22]}$ (see below). Astrocytes also provide a principal pathway for glutamate uptake: about $80 \%$ of all glutamate released during synaptic transmission, is taken up by astroglial cells with only about 20 per being accumulated into postsynaptic neurones; presynaptic neurones do not take up glutamate ${ }^{[20,23]}$.

Glutamate uptake by astroglial cells is mediated through plasmalemmal glutamate transporters of the solute carrier 1 (SLC1) family ${ }^{[24]}$ represented by 5 main types of Excitatory Amino Acid Transporters 1 - 5 (EAAT1/SLC1A3, EAAT2/SLC1A2, EAAT3/SLC1A1, EAAT4/SLC1A6 and EAAT5/SLC1A7), of which astrocytes specifically express EAAT-1 and EAAT-2 transporters; these in rodents are known as glutamate/aspartate transporter (GLAST) and glutamate transporter-1 (GLT-1). Transport of glutamate by EAATs is powered by transmembrane gradient of $\mathrm{Na}^{+}$ions; translocation of single molecule of glutamate (which is a monovalent anion at physiological $\mathrm{pH}$ ) is linked to an influx of three $\mathrm{Na}^{+}$ions, one $\mathrm{H}^{+}$ion and efflux of one $\mathrm{K}^{+}$ion, all these movements going downhill along with respective concentration gradients. The glutamate transport cycle, therefore, is associated with net cation influx which defines the electrogeneity of glutamate transporters that could be measured as an inward current. Uptake of physiologically relevant concentrations of glutamate causes substantial sodium influx, which may increase intracellular $\mathrm{Na}^{+}$concentration by tens of $\mathrm{mM}^{[25,26]}$.

\section{Astroglial release of glutamate}

Astrocytes can release glutamate by several different mechanisms: (i) reversal of uptake by plasma membrane glutamate transporters ${ }^{[27]}$, (ii) opening of anion channels, be that be volumeregulated anion channels ${ }^{[28]}$ or $\mathrm{Ca}^{2+}$-activated anion channels ${ }^{[29]}$, (iii) $\mathrm{Ca}^{2+}$-dependent exocytosis ${ }^{[30]}$, (iv) glutamate exchange via the cystine-glutamate antiporter ${ }^{[31]},(\mathrm{v})$ release through ionotropic purinergic receptors ${ }^{[32]}$ and (vi) functional unpaired connexons, "hemichannels", on 
the cell surface ${ }^{[33]}\left[\right.$ for review see ${ }^{[34]}$. These mechanisms can be further classified into the release through plasmalemmal molecular entities, channels and transporters, and by exocytosis, the latter characterized by the formation of an aqueous channel, the fusion pore, upon the merger of vesicular and plasma membranes. All of the mechanisms depend on glutamate concentration in various cellular compartments and the extracellular space. Conceptually, its anionic concentration gradient between the cytosol and the extracellular space directly dictates the release via plasmalemmal channels/transporters. However, due to coupling transport of other ions, EAATs have their reversal potential at $\sim+50 \mathrm{mV}^{[25,35]}$, which means that under normal physiological conditions EAATs could not revert to release glutamate ${ }^{[36]}$. In respect to exocytosis, cytosolic glutamate is sequestered into secretory vesicles via vesicular glutamate transports (VGLUTs) before it gets released through the fusion pore.

The cytoplasmic glutamate concentrations in astrocytes are maintained different than those in neurons [for review see ${ }^{[20]}$. The glutamate concentration in the cytosol of synaptic terminals reaches $10-15 \mathrm{mM}^{[37]}$. This permits VGLUTs $\left(\mathrm{K}_{\mathrm{m}} \sim 1-2 \mathrm{mM}\right)$ to operate at nearly their maximal rates to concentrate glutamate into synaptic vesicles. Consequently, intravesicular glutamate concentration reaches $60 \mathrm{mM}^{[38]}$, which generates estimated $\sim 1.1 \mathrm{mM}$ glutamate concentration in the synaptic cleft at time of release ${ }^{[39]}$. Owing to the powerful action of mainly astroglial EAATs, glutamate gets quickly lowered down, so that the resting glutamate concentration in the extracellular space of the CNS is maintained at $\sim 25 \mathrm{nM}^{[40]}$. Presumably due to the presence of GS, the cytosolic glutamate concentration in astrocytes is lower than neuronal at estimated 0.1-5 $\mathrm{mM}^{[37]}$. This is sufficient to allow for the operation of VGLUTs to concentrate glutamate inside astrocytic vesicles, which intravesicular concentration is estimated at about $\sim 20 \mathrm{mM}^{[41]}$. Consequently, vesicular glutamate release from astrocytes creates localized extracellular glutamate accumulations of $1-100 \mu \mathrm{M}^{[42]}$.

In the CNS, glutamate is synthesized de novo within astrocytes as a by-product of the tricarboxylic acid (TCA) cycle ${ }^{[43]}$. Here, as glucose breaks down to pyruvate in the cytosol, pyruvate enters mitochondria and the TCA cycle via pyruvate carboxylase, a ligase that catalyzes the carboxylation of pyruvate to form oxaloacetate (Fig. 1). In turn, glutamate is produced from $\alpha$-ketoglutarate, a downstream TCA intermediate, by transamination of aspartate via mitochondrial aspartate amino transferase. The synthesized glutamate once in the cytosol can then be converted to glutamine by GS, or transported into vesicles via VGLUTs, especially isoform 3 (VGLUT3) ${ }^{[44]}$ (Fig 2). The role of GS and cytosolic glutamate concentrations for exocytotic glutamate release from astrocytes has been experimentally demonstrated ${ }^{[44]}$. To increase the cytosolic glutamate concentration in astrocytes GS activity was blocked with L-methionine sulfoximine, which led to an augmented exocytotic glutamate release in response to mechanical stimulation ${ }^{[44]}$, while, importantly, $\mathrm{Ca}^{2+}$ dynamics were unaffected by this GS blocker. Of note, the mechanical stimulation almost exclusively $(97 \%$, based on the panVGLUT blocker Rose Bengal) recruits the exocytotic/vesicular release of glutamate ${ }^{[45]}$, but not glutamate release through, e.g., $\mathrm{Ca}^{2+}$-activated anion channels ${ }^{[46]}$. Therefore, the impairment of GS activity implicates that the increase of cytosolic glutamate concentration provided more 
glutamate for VGLUTs to transport across the vesicular membrane into the vesicular lumen, thus increasing the amount of glutamate in vesicles available for release. Further modulation of cytosolic glutamate concentration and its release could also originate from changes that might occur at the level of pyruvate carboxylase. Hence, astrocytes from a Huntington's disease mouse model showed an augmented glutamate release as de novo glutamate synthesis was increased due to an upsurge in the expression of pyruvate carboxylase, while the conversion of glutamate to glutamine was unchanged, as no changes in the expression level of GS were observed ${ }^{[47]}$. Hypothetically, additional modulation of cytosolic glutamate concentration could sprout from the metabolic pathway between pyruvate carboxylase and GS. This could involve various mitochondrial enzymes, such as the previously mentioned aspartate amino transferase. Similarly, SLCs redistributing reactants/products across the inner mitochondrial membrane could also be involved, perhaps mitochondrial glutamate carrier 1 (SLC family 25 member 22) and mitochondrial aspartate glutamate carrier (SLC family 25 member 13, also called citrin).

\section{Astroglial glutamine-glutamate and glutamine-GABA shuttle}

Maintenance of glutamatergic transmission requires constant replenishment of glutamate, which in turn relies on astroglial glutamate uptake, glutamate conversion into glutamine and transport of the latter into neuronal presynaptic terminals. This coordinated system of fluxes of glutamate and glutamine in generally known as glutamate-glutamine shuttle (Fig. 1). This is an energy dependent mechanism which requires hydrolysis of one molecule of ATP for a single conversion of glutamate to glutamine. Transport of glutamine from astrocytes and into neurones is mediated by amino-acid transporters, which have a specific distribution between neurones and astrocytes ${ }^{[48]}$. Astrocytes are in possession of the system $\mathrm{N}$ transporters (represented by $\mathrm{Na}^{+} / \mathrm{H}^{+}$ dependent sodium coupled neutral amino acid transporters SN1/SNAT3/SLC38A3 and SN2/SNAT5/SLC38A5 ${ }^{[49,50]}$ which mediate glutamine efflux. Importantly these transporters can be relatively easy switched to the reverse mode after, for example, increase in cytosolic $\mathrm{Na}+$ concentration. Neurones express another system for glutamine transport, mediated by the system A glutamine transporters [51] (the sodium coupled neutral amino acid transporters ATA1/SNAT1/SLC38A1 and ATA2/SNAT2/SLC38A2) which act as influx transporters mediating glutamine accumulation into the neuronal compartment ${ }^{[52]}$. There are some exceptions however, for example GABAergic neurones express N-transporter SNAT7 ${ }^{[53]}$.

In presynaptic terminals glutamine hydrolysed to glutamate; incidentally this conversion catalysed by phosphate-activated glutaminase, does not require energy. The newly synthesized glutamate is subsequently concentrated in synaptic vesicles bearing VGLUT transporters and thus releasable pool of glutamate is maintained. The supply of glutamate by astrocytes is coordinated with neuronal activity - increase in external concentration of glutamate increases release of glutamine ${ }^{[54]}$, this being mediated through glutamate transporters ${ }^{[5]}$ possibly through an increase in intracellular $\mathrm{Na}+$ concentration.

\section{Astroglia and GABA-ergic transmission}


Astroglial glutamine is also critical for inhibitory transmission in the CNS mediated by GABA. Presynaptic terminals synthetise GABA from glutamate that arrives through glutamate-glutamine shuttle; inhibition of the later rapidly inhibits GABAergic transmission ${ }^{[56]}$; this mechanism is often also referred to as GABA-glutamine shuttle or cycle (Fig. 2). The cytosolic concentration of GABA in astroglial cells can be quite high, approaching $2.5 \mathrm{mM}^{[57]}$. Of note, astrocytes also express GABA transporters GAT-1 and GAT-3, which can be readily reversed upon moderate (about $7 \mathrm{mM}$ ) increases in the cytosolic $\mathrm{Na}+$, thus making astrocytes the source of $\mathrm{GABA}^{[58]}$.

\section{Ammonia detoxification}

In addition to its importance in neurotransmission, GS also plays a significant role in the assimilation of ammonia by the brain. Ammonia, a metabolite mainly produced within the gastrointestinal system (through protein degradation and amino acid deamination), is primarily regulated by the urea cycle; exclusively found in the liver. Ammonia-rich venous blood from the gastrointestinal tract first passes through the liver maintaining the circulating concentration of ammonia between 35-50 $\mu \mathrm{M}$. Ammonia, composed of gas $\left(\mathrm{NH}_{3}\right)$ and ion $\left(\mathrm{NH}_{4}{ }^{+}\right)$components, can easily cross all plasma membranes through diffusion, channels and transporters ${ }^{[59]}$. In the setting of liver disease, blood ammonia levels can increase as high as $1 \mathrm{mM}$ leading to toxic concentrations in the brain and the onset of hepatic encephalopathy, a neuropsychiatric disorder involving cognitive alterations and motor impairments. Hyperammonemia also arises in infants with inborn errors of urea cycle enzymes causing seizures and coma. Surviving children have a high incidence of mental retardation and cerebral palsy. Toxic levels of ammonia trigger changes in both $\mathrm{pH}$ and membrane potential and have a profound effect on metabolism ${ }^{[59]}$. The brain is particularly susceptible to increased concentrations of ammonia and heavily relies on GS in astrocytes to prevent toxicity and neurological dysfunction. It has been demonstrated that an increase in brain ammonia elicits an increase in GS activity ${ }^{[60]}$ however Cooper et al. ${ }^{[61]}$ showed that under normal physiological conditions, GS activity in the brain operates at near maximal capacity, preventing any further induction. In either case, the observation of elevated concentrations of ammonia in liver disease reveals that the capacity of GS to detoxify ammonia in the brain is limited and therefore cannot compensate to maintain ammonia at physiological levels. Moreover, GS activity in brain has been shown to be inhibited in liver disease ${ }^{[62]}$ since an increase in cerebral nitric oxide stimulates peroxynitrite-mediated nitration of tyrosine residues of GS resulting in inactivation ${ }^{[63]}$. In turn, a decrease in capacity to clear ammonia in the brain detrimentally leads to sustained elevation in brain ammonia and, thus, persisting neurological dysfunction ${ }^{[64]}$.

\section{GS mutations in brain}

First described by Häberle et al., ${ }^{[65]}$, homozygous mutations in the GS gene (GLUL), as observed in two newborns lead to a reduction in GS activity and, consequently, severe brain malformations, seizures, multiorgan failure and early death. Surviving infants develop chronic 
encephalopathy during the neonatal period. Furthermore, mice with prenatal excisions of the GS gene die during early embryonic development ${ }^{[66]}$. Consequently, in addition to causing alterations in glutamate/glutamine homeostasis, deficiency in GS consequently impairs the detoxification of ammonia; concentrations of ammonia have been demonstrated to rise between 100-200 $\mu \mathrm{M}^{[67]}$. These levels of ammonia are comparable to those found in liver disease associated with hepatic encephalopathy ${ }^{[68]}$.

\section{CNS disorders and alterations in glutamine synthetase}

As GS is an essential part of a complex astrocyte-neuron signaling process, changes in expression and activity of GS will lead to neurological dysfunction. A number of different brain pathologies are associated with alterations in GS expression/activity. Patients diagnosed with medial lobe temporal lobe epilepsy exhibit markedly reduced GS expression and activity in the hippocampus despite astroglial proliferation/reactive astrocytes ${ }^{[69,70]}$.

However, an upregulation of GS has been demonstrated in the hippocampal dentate gyrus during seizure acquisition in the amygdala kindling model of epilepsy ${ }^{[71]}$ with, however, no change in GS activity found in frontal cortex of epilepsy patients ${ }^{[72]}$. Overall, it appears that alterations in GS activity/expression are region selective depending on the kind of epilepsy. Similarly, a decreased in GS expression was found in the striatum of rats with Parkinsonian tremor ${ }^{[73]}$. Postmortem brain tissue collected from Alzheimer's patients have revealed a reduction in GS activity ${ }^{[74,75]}$. Furthermore, it has been shown that the amount of GS protein in Alzheimer's brains is inversely correlated with the number of beta-amyloid plaques ${ }^{[76]}$ and that a decrease in GS is associated with the presence of amyloid beta deposits, as demonstrated in a mouse model of Alzheimer's disease ${ }^{[77]}$. Moreover, in the brains of patients with schizophrenia, an increase and decrease in GS mRNA has been found in specific regions as well ${ }^{[78]}$. Furthermore, there are several lines of evidence that support retinal GS is implicated in diabetic retinopathy. Down regulation of GS has been demonstrated to occur during the early stages of diabetes ${ }^{[79-81]}$. The susceptibility of certain brain structures damage (i.e CA1 area of the hippocampus) to hypoxic damage is associated with the disappearance of GS; this observation, however, has not been demonstrated in brain regions less susceptible to hypoxia ${ }^{[82]}$. Brain GS mRNA expression has also been found to be decreased in patients with depression ${ }^{[83-85]}$. In addition, increased expression of GS through ischemic postconditioning has been shown to be neuroprotective in ischemic rats ${ }^{[86]}$. Overall, changes in GS expression/activity are associated with neurodegenerative diseases and mental disorders (Fig. 3).

\section{GS expression in other brain cells?}

In addition to GS being particularly localized in astrocytes, GS expression has been measured in other cells of the brain. During pathophysiological conditions, such as in patients with Alzheimer's disease, GS was found to be expressed in neurons; a result that was not replicated in post-mortem tissue from control brains. Furthermore, GS has also been demonstrated to be expressed in microglia of simian immunodeficiency virus(SIV)-infected macaques ${ }^{[87]}$. However, 
the role of GS, as well as the cause or effect of GS expression in other cells of the brain, remains unclear $^{[88]}$.

\section{Conclusion}

Proper astrocyte function is imperative for glutamatergic/GABA physiology. Alterations in GS, an exclusive enzyme found in astrocytes, have been shown to be associated with a number of neurological disorders. In addition to GS playing a vital role in glutamate homeostasis, it is also bears the brunt of ammonia detoxification in the brain. The precise neurotoxic effects following alterations in GS, whether due to glutamate or ammonia neurotoxicity, deserves to be further investigated.

Acknowledgements. Authors' research was supported by Alzheimer's Research Trust (UK) Programme Grant (ART/PG2004A/1) to A.V. and by National Science Foundation (CBET 0943343) grant to V.P. 


\section{References}

[1] Verkhratsky A, Butt A. (2013) Glial Physiology and Pathophysiology. Chichester: WileyBlackwell; 2013.

[2] Kettenmann H, Ransom BR. (2013) Neuroglia. Oxford: Oxford University Press; 2013.

[3] Kimelberg HK. (2004) The problem of astrocyte identity. Neurochem. Int. 45, 191-202.

[4] Kimelberg HK. (2010) Functions of mature mammalian astrocytes: a current view. Neurosci. Rev. J. Bringing Neurobiol. Neurol. Psychiatry. 16, 79-106.

[5] Matyash V, Kettenmann H. (2010) Heterogeneity in astrocyte morphology and physiology. Brain Res. Rev. 63, 2-10.

[6] Verkhratsky A. (2010) Physiology of neuronal-glial networking. Neurochem. Int. 57, 33243.

[7] Zhang Y, Barres BA. (2010) Astrocyte heterogeneity: an underappreciated topic in neurobiology. Curr. Opin. Neurobiol. 20, 588-594.

[8] Parpura V, Verkhratsky A. (2012) Neuroglia at the crossroads of homoeostasis, metabolism and signalling: evolution of the concept. ASN Neuro. 4, 201-205.

[9] Parpura V, Verkhratsky A. (2012) Homeostatic function of astrocytes: $\mathrm{Ca}(2+)$ and $\mathrm{Na}(+)$ signalling. Transl. Neurosci. 3, 334-344.

[10] Kimelberg HK, Nedergaard M. (2010) Functions of astrocytes and their potential as therapeutic targets. Neurotherapeutics. 7, 338-353.

[11] Verkhratsky A, Parpura V, Rodríguez JJ. (2011) Where the thoughts dwell: the physiology of neuronal-glial “diffuse neural net.”Brain Res. Rev. 66, 133-151.

[12] Verkhratsky A, Rodríguez JJ, Parpura V. (2012) Calcium signalling in astroglia. Mol. Cell. Endocrinol. 353, 45-56.

[13] Pfrieger FW, Barres BA. (1996) New views on synapse-glia interactions. Curr Opin Neurobiol. 6, 615-621.

[14] Eroglu C, Barres BA. (2010) Regulation of synaptic connectivity by glia. Nature. 468, 223231.

[15] Kriegstein A, Alvarez-Buylla A. (2009) The glial nature of embryonic and adult neural stem cells. Annu. Rev. Neurosci. 32, 149-184. 
[16] Shimizu H, Watanabe E, Hiyama TY, Nagakura A, Fujikawa A, Okado H, et al. (2007) Glial Nax channels control lactate signaling to neurons for brain $[\mathrm{Na}+]$ sensing. Neuron. 54, 5972.

[17] Gourine AV, Kasparov S. (2011) Astrocytes as brain interoceptors. Exp. Physiol. 96, 411416.

[18] Gourine AV, Kasymov V, Marina N, Tang F, Figueiredo MF, Lane S, et al. (2010) Astrocytes control breathing through $\mathrm{pH}-$ dependent release of ATP. Science. 329, 571-575.

[19] Blutstein T, Haydon PG. (2013) The Importance of astrocyte-derived purines in the modulation of sleep. Glia. 61, 129-139.

[20] Danbolt NC. (2001) Glutamate uptake. Prog. Neurobiol. 65, 1-105.

[21] Boison D, Chen J-F, Fredholm BB. (2010) Adenosine signaling and function in glial cells. Cell Death Differ. 17, 1071-1082.

[22] Hertz L, Dringen R, Schousboe A, Robinson SR. (1999) Astrocytes: glutamate producers for neurons. J Neurosci Res. 57, 417-428.

[23] Eulenburg V, Gomeza J. (2010) Neurotransmitter transporters expressed in glial cells as regulators of synapse function. Brain Res. Rev. 63, 103-112.

[24] Kanai Y, Clémençon B, Simonin A, Leuenberger M, Lochner M, Weisstanner M, et al. (2013) The SLC1 high-affinity glutamate and neutral amino acid transporter family. Mol. Aspects Med. 34, 108-120.

[25] Kirischuk S, Kettenmann H, Verkhratsky A. (2007) Membrane currents and cytoplasmic sodium transients generated by glutamate transport in Bergmann glial cells. Pflugers Arch. 454, 245-252.

[26] Kirischuk S, Parpura V, Verkhratsky A. (2012) Sodium dynamics: another key to astroglial excitability? Trends Neurosci. 35, 497-506.

[27] Szatkowski M, Barbour B, Attwell D. (1990) Non-vesicular release of glutamate from glial cells by reversed electrogenic glutamate uptake. Nature. 348, 443-446.

[28] Kimelberg HK, Goderie SK, Higman S, Pang S, Waniewski RA. (1990) Swelling-induced release of glutamate, aspartate, and taurine from astrocyte cultures. J. Neurosci. Off. J. Soc. Neurosci. 10, 1583-1591.

[29] Oh S-J, Han K-S, Park H, Woo DH, Kim HY, Traynelis SF, et al. (2012) Protease activated receptor 1-induced glutamate release in cultured astrocytes is mediated by Bestrophin-1 
channel but not by vesicular exocytosis. Mol Brain. 5, 38-38.

[30] Parpura V, Basarsky TA, Liu F, Jeftinija K, Jeftinija S, Haydon PG. (1994) Glutamatemediated astrocyte-neuron signalling. Nature. 369, 744-747.

[31] Warr O, Takahashi M, Attwell D. (1999) Modulation of extracellular glutamate concentration in rat brain slices by cystine-glutamate exchange. J Physiol. 514 ( Pt 3), 783793.

[32] Duan S, Anderson CM, Keung EC, Chen Y, Chen Y, Swanson RA. (2003) P2X7 receptormediated release of excitatory amino acids from astrocytes. J Neurosci. 23, 1320-1328.

[33] Ye Z-C, Wyeth MS, Baltan-Tekkok S, Ransom BR. (2003) Functional hemichannels in astrocytes: a novel mechanism of glutamate release. J Neurosci. 23, 3588-3596.

[34] Malarkey EB, Parpura V. (2008) Mechanisms of glutamate release from astrocytes. Neurochem. Int. 52, 142-154.

[35] Bouvier M, Szatkowski M, Amato A, Attwell D. (1992) The glial cell glutamate uptake carrier countertransports $\mathrm{pH}$-changing anions. Nature. 360, 471-474.

[36] Longuemare MC, Swanson RA. (1997) Net glutamate release from astrocytes is not induced by extracellular potassium concentrations attainable in brain. J Neurochem. 69, 879-882.

[37] Attwell D, Barbour B, Szatkowski M. (1993) Nonvesicular release of neurotransmitter. Neuron. 11, 401-407.

[38] Burger PM, Mehl E, Cameron PL, Maycox PR, Baumert M, Lottspeich F, et al. (1989) Synaptic vesicles immunoisolated from rat cerebral cortex contain high levels of glutamate. Neuron. 3, 715-720.

[39] Clements JD, Lester RA, Tong G, Jahr CE, Westbrook GL. (1992) The time course of glutamate in the synaptic cleft. Science. 258, 1498-1501.

[40] Herman MA, Jahr CE. (2007) Extracellular glutamate concentration in hippocampal slice. J Neurosci. 27, 9736-9741.

[41] Montana V, Malarkey EB, Verderio C, Matteoli M, Parpura V. (2006) Vesicular transmitter release from astrocytes. Glia. 54, 700-715.

[42] Innocenti B, Parpura V, Haydon PG. (2000) Imaging extracellular waves of glutamate during calcium signaling in cultured astrocytes. J Neurosci. 20, 1800-1808. 
[43] Chen Y, Hertz L. (1999) Noradrenaline effects on pyruvate decarboxylation: correlation with calcium signaling. J Neurosci Res. 58, 599-606.

[44] Ni Y, Parpura V. (2009) Dual regulation of Ca2+-dependent glutamate release from astrocytes: vesicular glutamate transporters and cytosolic glutamate levels. Glia. 57, 12961305.

[45] Montana V, Ni Y, Sunjara V, Hua X, Parpura V. (2004) Vesicular glutamate transporterdependent glutamate release from astrocytes. J Neurosci. 24, 2633-2642.

[46] Woo DH, Han K-S, Shim JW, Yoon B-E, Kim E, Bae JY, et al. (2012) TREK-1 and Best1 channels mediate fast and slow glutamate release in astrocytes upon GPCR activation. Cell. 151, 25-40.

[47] Lee W, Reyes RC, Gottipati MK, Lewis K, Lesort M, Parpura V, et al. (2013) Enhanced $\mathrm{Ca}(2+)$-dependent glutamate release from astrocytes of the BACHD Huntington's disease mouse model. Neurobiol Dis. 58, 192-199.

[48] Chaudhry FA, Reimer RJ, Edwards RH. (2002) The glutamine commute: take the N line and transfer to the A. J. Cell Biol. 157, 349-355.

[49] Nakanishi T, Kekuda R, Fei YJ, Hatanaka T, Sugawara M, Martindale RG, et al. (2001) Cloning and functional characterization of a new subtype of the amino acid transport system N. Am. J. Physiol. Cell Physiol. 281, C1757-1768.

[50] Schiöth HB, Roshanbin S, Hägglund MGA, Fredriksson R. (2013) Evolutionary origin of amino acid transporter families SLC32, SLC36 and SLC38 and physiological, pathological and therapeutic aspects. Mol. Aspects Med. 34, 571-585.

[51] Chaudhry FA, Schmitz D, Reimer RJ, Larsson P, Gray AT, Nicoll R, et al. (2002) Glutamine uptake by neurons: interaction of protons with system a transporters. J. Neurosci. Off. J. Soc. Neurosci. 22, 62-72.

[52] Edwards RH. (2007) The neurotransmitter cycle and quantal size. Neuron. 55, 835-858.

[53] Hagglund MGA, Sreedharan S, Nilsson VCO, Shaik JHA, Almkvist IM, Backlin S, et al. (2011) Identification of SLC38A7 (SNAT7) protein as a glutamine transporter expressed in neurons. J Biol Chem. 286, 20500-20511.

[54] Martínez-Lozada Z, Guillem AM, Flores-Méndez M, Hernández-Kelly LC, Vela C, Meza E, et al. (2013) GLAST/EAAT1-induced glutamine release via SNAT3 in Bergmann glial cells: evidence of a functional and physical coupling. J. Neurochem. 125, 545-554.

[55] Uwechue NM, Marx M-C, Chevy Q, Billups B. (2012) Activation of Glutamate Transport 
Evokes Rapid Glutamine Release from Perisynaptic Astrocytes. J. Physiol. 590, 23172331.

[56] Jiang E, Yan X, Weng H-R. (2012) Glial glutamate transporter and glutamine synthetase regulate GABAergic synaptic strength in the spinal dorsal horn. J. Neurochem. 121, 526536.

[57] Lee M, McGeer EG, McGeer PL. (2011) Mechanisms of GABA release from human astrocytes. Glia. 59, 1600-1611.

[58] Unichenko P, Myakhar O, Kirischuk S. (2012) Intracellular Na+ concentration influences short-term plasticity of glutamate transporter-mediated currents in neocortical astrocytes. Glia. 60, 605-614.

[59] Bosoi CR, Rose CF. (2009) Identifying the direct effects of ammonia on the brain. Metab. Brain Dis. 24, 95-102.

[60] Cudalbu C, Lanz B, Duarte JM, Morgenthaler FD, Pilloud Y, Mlynárik V, et al. (2012) Cerebral glutamine metabolism under hyperammonemia determined in vivo by localized (1)H and (15)N NMR spectroscopy. J. Cereb. Blood Flow Metab. Off. J. Int. Soc. Cereb. Blood Flow Metab. 32, 696-708.

[61] Cooper AJ, Plum F. (1987) Biochemistry and physiology of brain ammonia. Physiol. Rev. 67, 440-519.

[62] Schliess F, Görg B, Fischer R, Desjardins P, Bidmon HJ, Herrmann A, et al. (2002) Ammonia induces MK-801-sensitive nitration and phosphorylation of protein tyrosine residues in rat astrocytes. FASEB J. 16, 739-741.

[63] Görg B, Wettstein M, Metzger S, Schliess F, Häussinger D. (2005) Lipopolysaccharideinduced tyrosine nitration and inactivation of hepatic glutamine synthetase in the rat. Hepatology. 41, 1065-1073.

[64] Rose C, Felipo V. (2005) Limited capacity for ammonia removal by brain in chronic liver failure: potential role of nitric oxide. Metab. Brain Dis. 20, 275-83.

[65] Häberle J, Görg B, Toutain A, Rutsch F, Benoist J-F, Gelot A, et al. (2006) Inborn error of amino acid synthesis: human glutamine synthetase deficiency. J. Inherit. Metab. Dis. 29, $352-8$.

[66] He Y, Hakvoort TBM, Vermeulen JLM, Lamers WH, Van Roon M a. (2007) Glutamine synthetase is essential in early mouse embryogenesis. Dev. Dyn. Off. Publ. Am. Assoc. Anat. 236, 1865-75. 
[67] Häberle J. (2011) Clinical practice: the management of hyperammonemia. Eur. J. Pediatr. 170, 21-34.

[68] Rose CF. (2012) Ammonia-Lowering Strategies for the Treatment of Hepatic Encephalopathy. Clin. Pharmacol. Ther. 92, 321-331.

[69] Eid T, Thomas MJ, Spencer DD, Rundén-Pran E, Lai JCK, Malthankar GV, et al. (2004) Loss of glutamine synthetase in the human epileptogenic hippocampus: possible mechanism for raised extracellular glutamate in mesial temporal lobe epilepsy. Lancet. 363, $28-37$.

[70] Van der Hel WS, Notenboom RGE, Bos IWM, van Rijen PC, van Veelen CWM, de Graan PNE. (2005) Reduced glutamine synthetase in hippocampal areas with neuron loss in temporal lobe epilepsy. Neurology. 64, 326-333.

[71] Sun H-L, Zhang S-H, Zhong K, Xu Z-H, Feng B, Yu J, et al. (2013) A Transient Upregulation of Glutamine Synthetase in the Dentate Gyrus Is Involved in Epileptogenesis Induced by Amygdala Kindling in the Rat. PloS One. 8, e66885.

[72] Steffens M, Huppertz H-J, Zentner J, Chauzit E, Feuerstein TJ. (2005) Unchanged glutamine synthetase activity and increased NMDA receptor density in epileptic human neocortex: implications for the pathophysiology of epilepsy. Neurochem. Int. 47, 379-384.

[73] Yu X, He G-R, Sun L, Lan X, Shi L-L, Xuan Z-H, et al. (2012) Assessment of the treatment effect of baicalein on a model of Parkinsonian tremor and elucidation of the mechanism. Life Sci. 91, 5-13.

[74] Hensley K, Hall N, Subramaniam R, Cole P, Harris M, Aksenov M, et al. (1995) Brain Regional Correspondence Between Alzheimer's Disease Histopathology and Biomarkers of Protein Oxidation. J. Neurochem. 65, 2146-2156.

[75] Smith CD, Carney JM, Starke-Reed PE, Oliver CN, Stadtman ER, Floyd RA, et al. (1991) Excess brain protein oxidation and enzyme dysfunction in normal aging and in Alzheimer disease. Proc. Natl. Acad. Sci. U. S. A. 88, 10540-10543.

[76] Prince GL, Delaere P, Fages C, Lefrançois T, Touret M, Salanon M, et al. (1995) Glutamine synthetase (GS) expression is reduced in senile dementia of the Alzheimer type. Neurochem. Res. 20, 859-862.

[77] Olabarria M, Noristani HN, Verkhratsky A, Rodríguez JJ. (2011) Age-dependent decrease in glutamine synthetase expression in the hippocampal astroglia of the triple transgenic Alzheimer's disease mouse model: mechanism for deficient glutamatergic transmission? Mol. Neurodegener. 6, 55. 
[78] Steffek AE, McCullumsmith RE, Haroutunian V, Meador-Woodruff JH. (2008) Cortical expression of glial fibrillary acidic protein and glutamine synthetase is decreased in schizophrenia. Schizophr. Res. 103, 71-82.

[79] Lieth E, Barber AJ, Xu B, Dice C, Ratz MJ, Tanase D, et al. (1998) Glial reactivity and impaired glutamate metabolism in short-term experimental diabetic retinopathy. Penn State Retina Research Group. Diabetes. 47, 815-820.

[80] Xu-hui Y, Hong Z, Yu-hong W, Li-juan Liu, Yan T, Ping L. (2009) Time-dependent reduction of glutamine synthetase in retina of diabetic rats. Exp. Eye Res. 89, 967-971.

[81] Fernandez DC, Pasquini LA, Dorfman D, Aldana Marcos HJ, Rosenstein RE. (2012) Ischemic conditioning protects from axoglial alterations of the optic pathway induced by experimental diabetes in rats. PloS One. 7, e51966.

[82] Lee A, Lingwood BE, Bjorkman ST, Miller SM, Poronnik P, Barnett NL, et al. (2010) Rapid loss of glutamine synthetase from astrocytes in response to hypoxia: implications for excitotoxicity. J. Chem. Neuroanat. 39, 211-220.

[83] Sequeira A, Mamdani F, Ernst C, Vawter MP, Bunney WE, Lebel V, et al. (2009) Global Brain Gene Expression Analysis Links Glutamatergic and GABAergic Alterations to Suicide and Major Depression. PLoS ONE. 4, e6585.

[84] Choudary PV, Molnar M, Evans SJ, Tomita H, Li JZ, Vawter MP, et al. (2005) Altered cortical glutamatergic and GABAergic signal transmission with glial involvement in depression. Proc. Natl. Acad. Sci. U. S. A. 102, 15653-15658.

[85] Klempan TA, Sequeira A, Canetti L, Lalovic A, Ernst C, ffrench-Mullen J, et al. (2009) Altered expression of genes involved in ATP biosynthesis and GABAergic neurotransmission in the ventral prefrontal cortex of suicides with and without major depression. Mol. Psychiatry. 14, 175-189.

[86] Zhang W, Miao Y, Zhou S, Jiang J, Luo Q, Qiu Y. (2011) Neuroprotective effects of ischemic postconditioning on global brain ischemia in rats through upregulation of hippocampal glutamine synthetase. J. Clin. Neurosci. Off. J. Neurosurg. Soc. Australas. 18, 685-689.

[87] Chrétien F, Vallat-Decouvelaere A-V, Bossuet C, Rimaniol A-C, Le Grand R, Le Pavec G, et al. (2002) Expression of excitatory amino acid transporter-2 (EAAT-2) and glutamine synthetase (GS) in brain macrophages and microglia of SIVmac251-infected macaques. Neuropathol. Appl. Neurobiol. 28, 410-417.

[88] Gras G, Samah B, Hubert A, Léone C, Porcheray F, Rimaniol A-C. (2012) EAAT 
expression by macrophages and microglia: still more questions than answers. Amino Acids. 42, 221-229. 


\section{Figure legends}

Figure 1: Astrocytes maintain glutamatergic and GABA-ergic transmissions through glutamate-glutamine and GABA-glutamine shuttle.

After entering the astrocyte, glutamate is converted into glutamine, which is then transported back to the presynaptic terminals, where it is converted into glutamate in excitatory and into GABA in inhibitory synapses; these neurotransmitters subsequently are accumulated into synaptic vesicles.

Figure 2: Regulation of glutamate in exocytotic glutamate release from astrocytes. Glucose is broken down to pyruvate in the cytosol. In the mitochondrion (mito) pyruvate entry through the tricarboxylic acid cycle via pyruvate carboxylase (PC) leads to production of oxaloacetate (OAA) and a downstream intermediate, $\alpha$-ketoglutarate $(\alpha-\mathrm{KG})$. In turn, glutamate (Glut) is synthesized in astrocytes de novo from $\alpha-\mathrm{KG}$ by transamination of aspartate via mitochondrial aspartate amino transferase (AAT). The synthesized glutamate once in the cytosol can then be converted to glutamine (Gln) by glutamine synthetase (GS), or transported into vesicles via vesicular glutamate transporters, especially isoform 3 (VGLUT3). Drawing is not to scale.

Figure 3: Alterations in GS and neuropathologies 


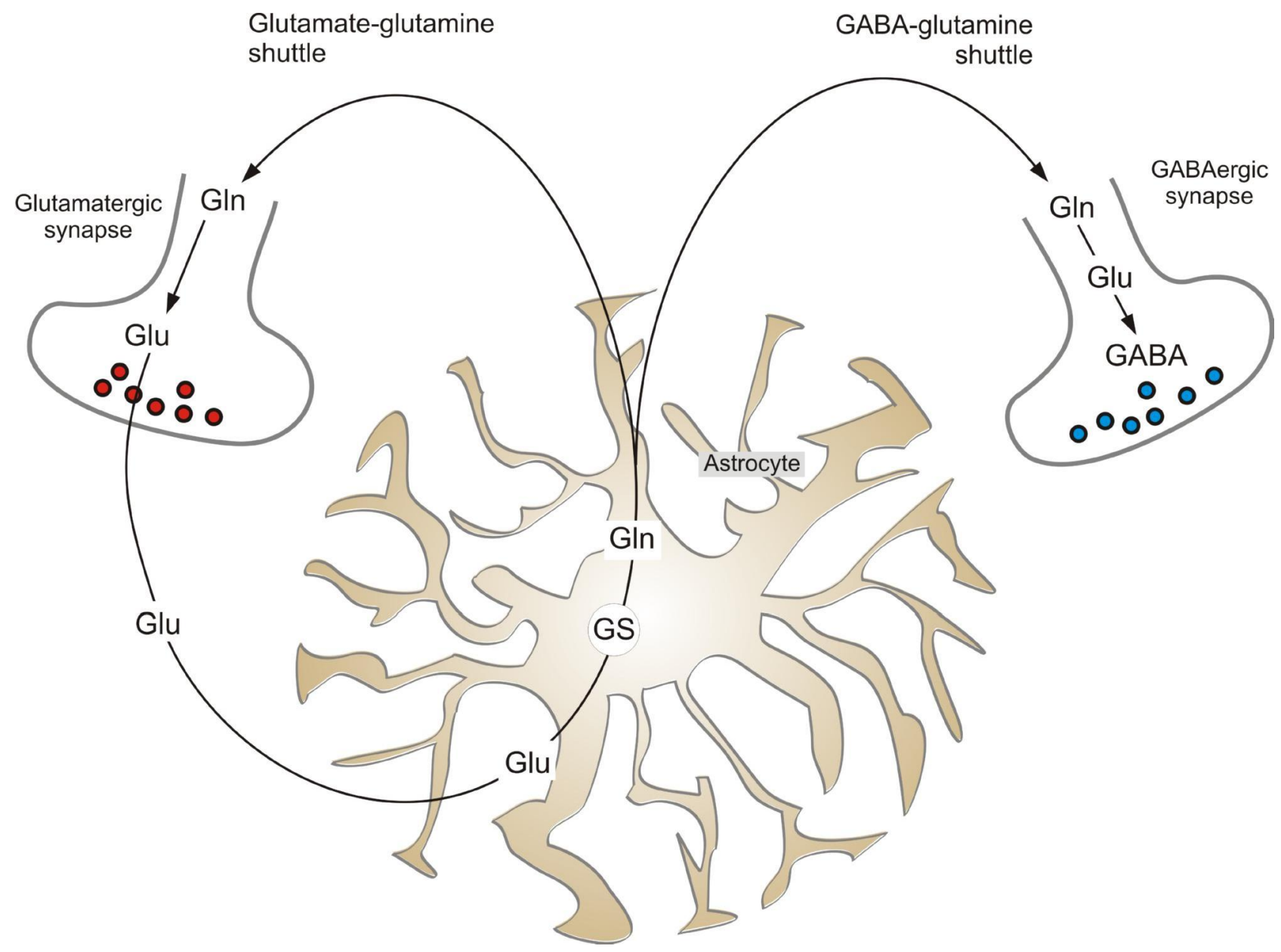




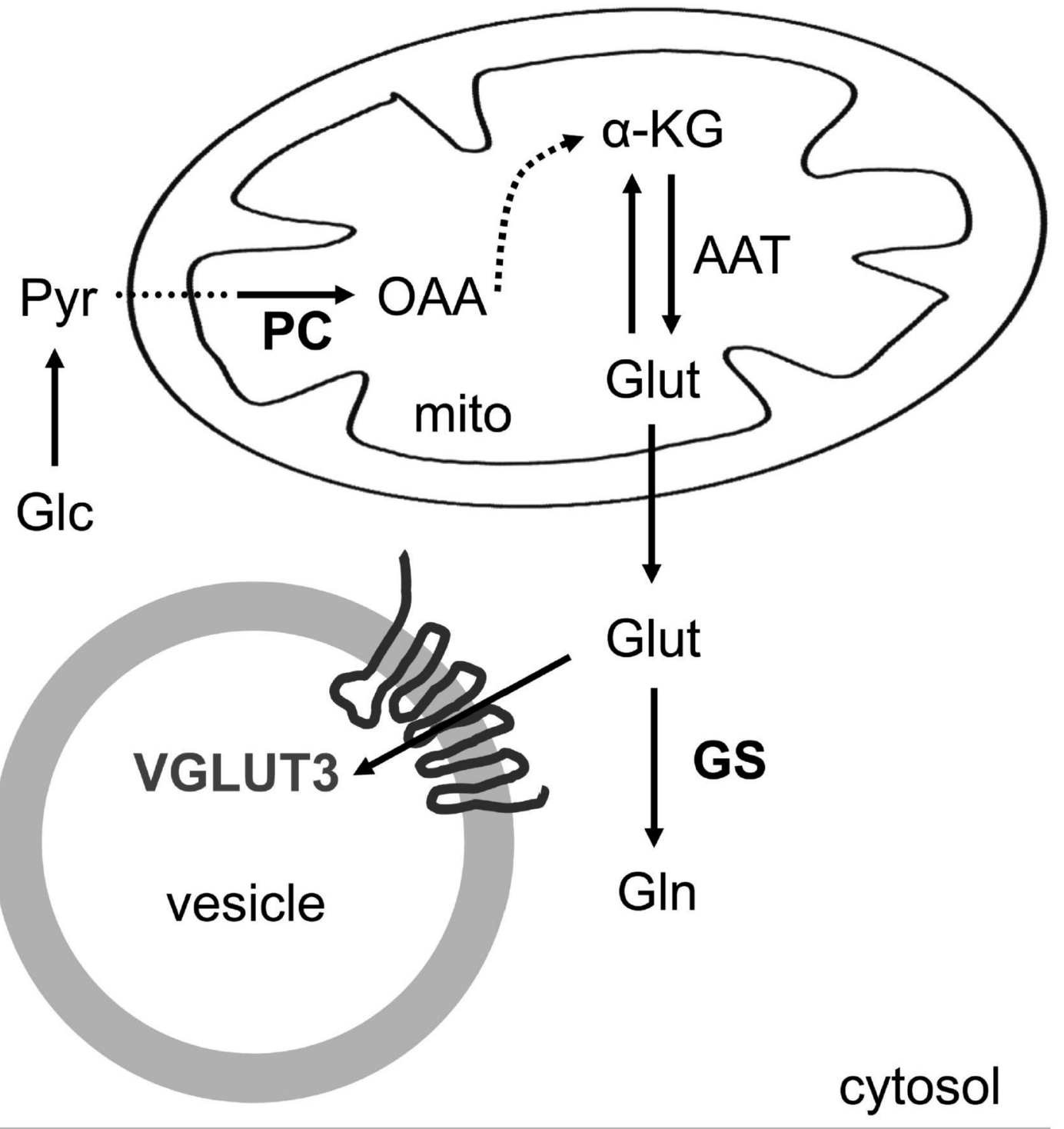

plasma membrane 


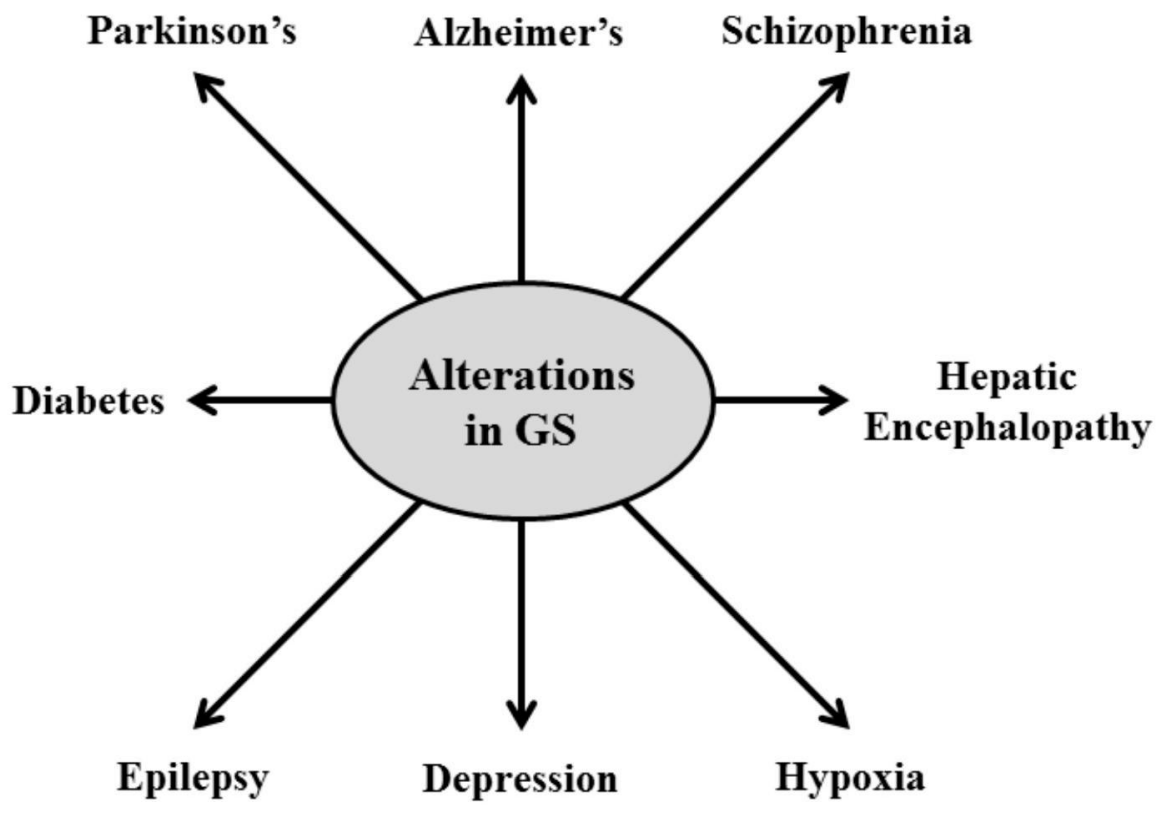

